\title{
Regularities of beet root crop yield formation based on retrospective data
}

\author{
Elena Melikhova, ${ }^{1, *}$ \\ ${ }^{1}$ Volgograd State Agrarian University, Ave Universitetsky, 26, Volgograd, 400002, Russia
}

\begin{abstract}
The article presents a statistical model of the impact of agromeliorative factors, including methods and modes of irrigation on the productivity of beet root crops in the combination of drip irrigation and fine sprinkling (MAV). The experiments were carried out according to a three - factor scheme providing for the regulation of the phytoclimate (factor A): A1 - drip irrigation; A2-drip irrigation together with the management of the phytoclimate by MAV. Hydrothermal regulation of the phytoclimate was carried out using additional equipment with an interval of 1 hour during the entire vegetation period, provided that the air temperature was higher than the biologically optimal $26^{\circ} \mathrm{C}$. the parameters of controlling the lowest humidity of HB (factor B) were taken: B1 - 70\%; $\mathrm{B} 2-80 \%$. On the basis of the dispersion statistical analysis of the results of field studies, the following statistically significant shares of their participation in the formation of the crop were established: factor $\mathrm{A}-23 \%$, factor B $-29 \%$, factor $\mathrm{C}-44 \%$. The revealed joint influence of factors $\mathrm{A}$ and $\mathrm{C}$ on the variability of the crop of root crops, the share of which was two percent, exceeds the value of the influence of other pair interactions.
\end{abstract}

\section{Introduction}

Improving resource-saving irrigation technologies, in particular combined irrigation [1], requires multi-factor field studies that reveal the degree of their influence. The problem of statistically reliable mathematical modeling of crop productivity based on the results of multi-factor field experiments is due to its significant variability when cultivated under similar agrometeorological conditions. This is caused by the mutual influence of various biological, agrotechnological, and climatic factors [2,3]. According to a number of authors [4-8], it is difficult to construct reliable mathematical models of variation in yield levels for new technologies being developed, in particular combined irrigation. In this regard, to take into account the complex influence of the irrigation regime and agrotechnical factors, the most reliable method is the construction of statistical models using multivariate analysis of variance (MAV).

\footnotetext{
*Corresponding author: evmelihova@gmail.com
} 


\section{Methods and materials}

Field studies of the variability of table beet yield were conducted in 2012...2015 in collaboration an irrigated experimental plot of the Leninsky district of the Volgograd region when sowing the zoned hybrid Castrel F1. The area of the experimental site was 2 ha. The soil cover of the site is represented by light and medium loamy soils. The physicalmechanical and hydrological properties of the soil were determined using generally accepted methods. In the studied variants, the soil and hydrological conditions, as well as the microclimate, were the same. The predecessor was the bow.

In order to exclude the influence of soil differences on the resulting yield, a three-fold repetition of the studied variants of the combination of factors was taken. To eliminate the mutual influence of the studied variants, protective strips with a width of $2.5,10.0$ and $50 \mathrm{~m}$ were provided.

The experiments were based on a three-factor scheme, which provides for the following levels of variation of factors.

Irrigation phytoclimatic management (factor A): A1-drip irrigation; A2-drip irrigation together with phytoclimatic management using MAV). Hydrothermal control of the phytoclimatic was carried out using additional equipment at intervals of 1 hour during the entire growing season, provided that the air temperature exceeded the biologically optimal $260 \mathrm{C}$.

The parameters for controlling the lowest (maximum) humidity (factor B) were taken: B1-70 \%; B2-80 \% HB. Studies by a number of scientists $[4,6,8]$ have shown that the range of the lowest moisture capacity of $70-80 \%$ of the total porosity has a favorable effect on the development of crops, maintaining humidity up to $80-90 \% \mathrm{HB}$ - mediocre effect on productivity, and over $90 \%$ - unsatisfactory due to insufficient air content in the soil.

The level of mineral nutrition (factor $\mathrm{C}$ ), calculated for the predicted yield of 60,70 , and $80 \mathrm{C} / \mathrm{ha}$, respectively, was maintained: C1-N60P30K40; C2 - N100P80K60; C3 N120P100K80 [2,3].

Kestrel F1 hybrid beets were sown in the second decade of may. Table beet sowing was two-line, the distance between the ribbons was $0.6 \mathrm{~m}$, between the seeds-5 ... $6 \mathrm{~cm}$, between the lines was kept $8 \pm 1 \mathrm{~cm}$. Irrigation pipes are placed between the lines after cultivation between the rows. For each dropper, there are $6 \ldots 8$ root vegetables. The hourly capacity of droppers is about 4 liters. Irrigation standards were provided by maintaining the pressure level at the pump. Placement of droppers after $20 \mathrm{~cm}$ provided complete closure of the moisture contours under the soil surface, providing a value of the moisture coefficient in the range of $0.70 \ldots 0.90$.

Table 1. Parameters of table beet irrigation.

\begin{tabular}{|l|c|c|c|c|c|c|}
\hline Period & \multirow{2}{*}{$\begin{array}{l}\text { Number of } \\
\text { watering }\end{array}$} & \multicolumn{2}{|c|}{ Irrigation rate. } & \multicolumn{2}{|c|}{ Irrigates norm } & \multirow{2}{*}{$\begin{array}{l}\text { Duration of } \\
\text { irrigation, } \mathrm{h}\end{array}$} \\
\cline { 3 - 6 } & 22 & 4.4 & 43.6 & 96.8 & 959.2 & 1.25 \\
\hline June & 30 & 4.4 & 43.9 & 132 & 1317 & 3.00 \\
\hline July & 25 & 4.4 & 44.2 & 110 & 1105 & 3.68 \\
\hline August & 10 & 4.9 & 49 & 49 & 490 & 2.83 \\
\hline September & 87 & 4.53 & 45.18 & 96.95 & 967.8 & 2.69 \\
\hline $\begin{array}{l}\text { During the } \\
\text { irrigation } \\
\text { period (on } \\
\text { average) }\end{array}$ & & & & & & \\
\hline
\end{tabular}

Taking into account the calculated irrigation standards, a drip irrigation regime was developed, presented in table 1. Irrigation was assigned depending on the irrigation regime. 
The average values of the irrigation regime parameters for the variants (factor B) are shown in table 1 .

The complexity of practical processing of field experiment materials by the MAV method is due to the cumbersome calculations [5,9], the lack of available specialized software, or the need to adapt universal statistical data processing packages (Statistica, Statgrafics, etc.) to the features (experience scheme, repetition) of multi-factor field studies. In this regard, the results of field experiments were processed by the MAV method using it in the MathCad 15 environment using a computer program developed at the Department of mathematical modeling and computer science of the Volgograd state UNIVERSITY $[9,10]$. The original $\mathrm{x}$ yield matrix is set in the MS EXCEL table processor format. The developed MAV program automatically determines the number of columns in the input matrix $\mathrm{X}$ of yields for the repeatability of experiments (Fig. 1).

The developed program was tested as follows. As a test analog of the three-factor experiment, we used the variant, the initial data and the results of the analysis of variance, which are published in the methodology of field experience [5]. A comparison of the results obtained and similar calculations given in table 75 of the "field experience Methods" confirmed their agreement with an accuracy of up to hundredths. The conducted testing of the developed program confirms the possibility of its use for MAV results of field experiments.

\section{Results}

The matrix $X$ of input data for statistical processing by the MAV method is shown in figure 1, which shows the yield of root crops with a three-time repetition of experiments in 2015 . A fragment of the program in the Mathcad environment is shown in figure 1.

\begin{tabular}{|c|c|c|c|}
\hline \multicolumn{4}{|l|}{$X:=$} \\
\hline & 1 & 2 & 3 \\
\hline 1 & 63.1 & 63.3 & 63.4 \\
\hline 2 & 65.2 & 66.2 & 65.8 \\
\hline 3 & 68.4 & 68.6 & 68.5 \\
\hline 4 & 67.5 & 67.6 & 67.5 \\
\hline 5 & 68.2 & 68.9 & 68.7 \\
\hline 6 & 71.5 & 71.8 & 71.6 \\
\hline 7 & 66.4 & 66.3 & 66 \\
\hline 8 & 68.3 & 68.6 & 68.8 \\
\hline 9 & 71.6 & 71.4 & 71.7 \\
\hline 10 & 68.5 & 68.6 & 68.7 \\
\hline 11 & 72.4 & 73.5 & 74.8 \\
\hline 12 & 76.5 & 76.8 & 76.7 \\
\hline
\end{tabular}

Fig. 1. Input of initial data for MAV.

The results of the variance analysis of a multi-factor field experiment on the study of variability of root crop yield, performed according to the proposed program, are presented in table 2 . 
Table 2. Results of the dispersion analysis of the influence of the main agromeliorative factors on the yield of root crops.

\begin{tabular}{|c|c|c|c|c|c|c|c|c|}
\hline $\begin{array}{l}\text { Dispersion } \\
\text { Дисперсия }\end{array}$ & $\begin{array}{c}\sum \\
\text { square } \\
\text { s of } \\
\text { variati } \\
\text { on }\end{array}$ & $\begin{array}{l}\text { Degre } \\
\text { e of } \\
\text { freedo } \\
\mathrm{m}\end{array}$ & $\begin{array}{c}\text { Mean } \\
\text { square } \\
\text { of } \\
\text { deviati } \\
\text { ons }\end{array}$ & $F_{\text {fact }}$ & $F_{05}$ & $S d$ & $\mathrm{HCP}_{05}$ & \begin{tabular}{|c|} 
Contribu \\
tion to \\
variance, \\
$\%$
\end{tabular} \\
\hline General, Cy & 344,98 & 23 & & & & & & \\
\hline Reps, Cp & 0,052 & 2 & & & & & & \\
\hline $\begin{array}{l}\text { Irrigation } \\
\text { parameter, CA }\end{array}$ & 55,2 & 1 & 55,2 & 2889 & 4,6 & 0,056 & 0,121 & 22,56 \\
\hline Irrigation mode, SV & 82,9 & 1 & 82,9 & 4338 & 4,6 & 0,056 & 0,121 & 29,35 \\
\hline $\begin{array}{ll}\text { Power } & \text { supply } \\
\text { background, SS }\end{array}$ & 193,8 & 1 & 193,8 & 10140 & 4,6 & 0,056 & 0,121 & 44,05 \\
\hline $\mathrm{Cab}$ & 0,002 & 1 & 0,002 & 0,087 & 4,6 & 0,08 & 0,171 & 0,28 \\
\hline $\mathrm{Cac}$ & 6,202 & 1 & 6,202 & 324,6 & 4,6 & 0,08 & 0,171 & 1,75 \\
\hline$C b c$ & 0,96 & 1 & 0,96 & 50,24 & 4,6 & 0,08 & 0,171 & 0,24 \\
\hline$C a b c$ & 5,607 & 1 & 5,607 & 293,43 & 4,6 & 0,113 & 0,242 & 1,77 \\
\hline Residual, $\mathrm{Cz}$ & 0,27 & 14 & 0,01 & - & & & & \\
\hline
\end{tabular}

Table 2 summarizes the data used to test the null hypothesis about the significance of the influence of the studied factors on the yield of table beet according to Fischer's F criterion, determine the error values of the average $\mathrm{Sd}$, as well as the difference between the average values and the materiality criterion (NSR05) for the separate and mutual action of the studied factors and the share of their influence.

Comparison of the actual and theoretical values of the Fisher criterion shows that in cases where the condition is met

$$
\text { Ffact }>\text { F05, }
$$

The effect and interaction of factors in the analyzed experience is significant.

The significance of the factors and their interaction is determined by calculating the average error $\mathrm{Sx}$, the error of the difference in the average $\mathrm{Sd}$, and the possible limit error or the smallest significant difference NSR.

The analysis made it possible to evaluate the significance of differences in group average yields of root crops depending on the studied factors using Fischer's F-criterion.

\section{Discussion}

To statistically assess the significance of the influence of the studied factors and their interactions (Fig. 2), the error of the Sd average and NSR at the 5\% level was calculated using the student's criterion. The calculated values of the student's T05 criterion were obtained taking into account the degrees of freedom using the built-in functions of the MathCad environment. 


$$
\mathrm{D}=\left(\begin{array}{cccccc}
\text { "Faktor" } & \text { "Sum. kvadr." } & \text { "\% vklad" } & \text { "Sx" } & \text { "Sd" } & \text { "HCP05" } \\
\text { "A" } & 99.334 & 22.563 & 0.088 & 0.124 & 0.258 \\
\text { "B" } & 129.201 & 29.347 & 0.088 & 0.124 & 0.258 \\
\text { "C" } & 193.944 & 44.052 & 0.108 & 0.152 & 0.316 \\
\text { "AB" } & 1.21 & 0.275 & 0.124 & 0.176 & 0.364 \\
\text { "AC" } & 7.704 & 1.75 & 0.152 & 0.215 & 0.446 \\
\text { "BC" } & 1.054 & 0.239 & 0.152 & 0.215 & 0.446 \\
\text { "ABC" } & 7.812 & 1.774 & 0.215 & 0.304 & 0.631
\end{array}\right)
$$

Fig. 2. Matrix of factor shares and their paired and triple interactions.

For estimating the net impact of each factor:

$$
S d=\sqrt{\frac{2 S^{2} \cdot l_{a}}{N}},
$$

where is the calculated Sd - average error; S2 - average value of the error square (group and intra-group variances).

The HCP values were determined by dependence (3):

$$
\mathrm{HCP} 05=t 05 \cdot \mathrm{Sd} \text {, }
$$

During the MAV, the shares of the contribution of agromeliorative factors in the total level of crop formation were also revealed. For clarity of the analysis, see table. 2 statistically insignificant combinations of factors are highlighted in gray.

The main influence of the studied agromeliorative factors and their paired and triple combinations on the formation of table beet yield is shown in Fig. 3.

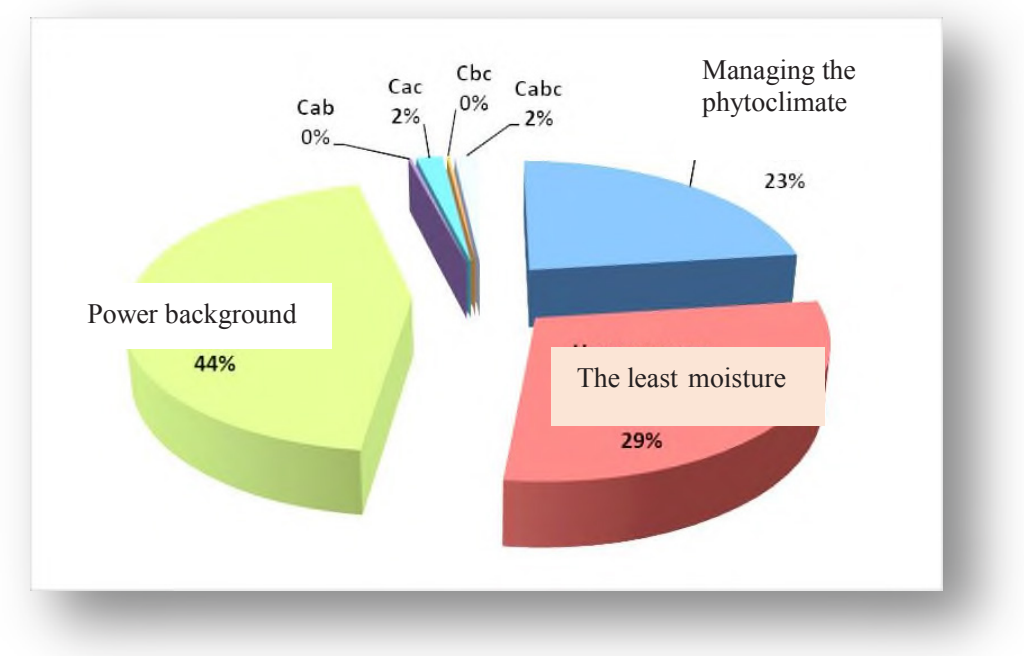

Fig. 3. Diagram of the influence of factors on the formation of table beet yield. 


\section{Conclusions}

For statistical processing, the developed program for multivariate analysis of variance of multivariate field experiments was used. Based on the developed MAV program, the results of the variance analysis of three-factor field studies, a statistical model of the influence of the main agromeliorative factors on the yield of table beet was obtained and the following significant shares of their participation in crop formation were identified: factor A-23\%, factor B-29\%, factor C-44\%. The combined effect of AIS factors on the variability of the table beet crop, which is about two percent, exceeds the share of other paired interactions of $\mathrm{AC}$ and $\mathrm{ABC}$ (Fig. 3). This confirms the expediency of improving reclamation technologies for table beet cultivation, taking into account the influence of the above factors.

\section{References}

1. V.V. Vasilenko, S.V. Vasilenko, Traction resistance at the tillage wedge, Research Journal of Pharmaceutical, Biological and Chemical Sciences 10, 2, 1126-1131 (2019)

2. J. Sexton, Y. Everingham, D. Donald, A Comparison of data mining algorithms for improving nir models of cane quality measures. 39th Conference of the Australian Society of Sugar Cane Technologists, ASSCT 2017, 39, 557-567 (2017)

3. V.V. Vasilenko, S.V. Vasilenko, N.N. Achkasova, Impact of precision seeding on yield of sugar beet, Advances in Engineering Research 776-778 (2018)

4. V.I. Burenin, A.V. Emeljanov, T.M. Piskunova, D.V. Sokolova, Catalog of the world collection of VIR, Characterization of beet accessions in connection with problems of adaptability 791 (2009)

5. R.V. Kravchenko, Agrobiological basis for obtaining stable corn grain yields in the 116 conditions of the steppe zone of Central Ciscaucasia: monograph (2010)

6. V.V. Vasilenko, S.V. Vasilenko, Analytical determination of the rational angle of lifting: the soil cooking organ. IOP Conference Series: Earth and Environmental Science. The proceedings of the conference AgroCON-2019, 012122 (2019)

7. S.K. Singla, R.D. Garg, O.P. Dubey, Machine learning models to estimate the sugarcane brix values from multitemporal vegetation indices. Proceedings of International Conference on Computation, Automation and Knowledge Management, ICCAKM 177-183 (2020)

8. E.V. Melikhova, A.F. Rogachev, N.N. Skiter, Information System and Database for Simulation of Irrigated Crop Growing, Studies in Computational Intelligence 826, 1185-1191 (2019)

9. E. Melikhova, A. Rogachev, Computer Simulation and Optimization of Parameters of Configuration of the Contour of Moistening Under Drip Irrigation of Agricultures, Studies in computational intelligence 826, 78-88 (2019)

10. A.F. Rogachev, Fuzzy Set Modeling of Regional Food Security, Advances in Intelligent Systems and Computing 726, 774-782 (2019) doi: 10.1007/978-3-319-90835-9_89 